\title{
Autonomy in place of birth: a concept analysis
}

\author{
Berglind Halfdansdottir • Margaret E. Wilson • \\ Ingegerd Hildingsson - Olof A. Olafsdottir • \\ Alexander Kr. Smarason · Herdis Sveinsdottir
}

Published online: 3 February 2015

(C) Springer Science+Business Media Dordrecht 2015

\begin{abstract}
This article examines one of the relevant concepts in the current debate on home birth-autonomy in place of birth - and its uses in general language, ethics, and childbirth health care literature. International discussion on childbirth services. A concept analysis guided by the model of Walker and Avant. The authors suggest that autonomy in the context of choosing place of birth is defined by three main attributes: information, capacity and freedom; given the antecedent of not harming others, and the consequences of accountability for the outcome. Model, borderline and contrary cases of autonomy in place of birth are presented. A woman choosing place of birth is autonomous if she receives all relevant information on available choices, risks and benefits, is capable of understanding and processing the information and choosing place of birth in the absence of coercion, provided she intends no harm to others and is accountable for the outcome. The attributes of the definition can serve as a useful tool for pregnant women,
\end{abstract}

B. Halfdansdottir $(\bowtie) \cdot$ O. A. Olafsdottir $\cdot$ H. Sveinsdottir University of Iceland, Eirberg, Eiriksgata 34, 101 Reykjavik, Iceland

e-mail: beh6@hi.is

M. E. Wilson

University of Nebraska Medical Center, Omaha, Nebraska

I. Hildingsson

Mid Sweden University, Sundsvall, Sweden

I. Hildingsson

Karolinska Institutet, Stockholm, Sweden

I. Hildingsson

Uppsala University, Uppsala, Sweden

A. Kr. Smarason

University of Akureyri, Akureyri, Iceland midwives, and other health professionals in contemplating their moral status and discussing place of birth.

Keywords Autonomy - Choice - Concept analysis . Home birth · Midwifery $\cdot$ Place of birth

\section{Introduction}

In the last decades home birth has become a controversial topic among health professionals, academics, and the general public. Stakeholders' opposing attitudes towards home birth and lack of mutual understanding have made the discussion a challenging one (Vedam 2012). The debate is set against the backdrop of observational studies on home birth, which, on comparison with hospital birth, seems to have similar or better outcome for mother and baby in low-risk situations (Olsen and Clausen 2012). These findings, welcomed by some and scrutinized by others, in the absence of a body of randomized controlled trials, have yet to provide the basis for reconciliation of opposing views.

In any discussion on informed choice in health care, the individual's autonomy is a pivotal concept (Dworkin 1988). The differences in the ways the autonomy concept itself is understood, both in general and situation-specific terms (Dworkin 1988), may be a part of the divide in the discussion on choice in home birth. Finding a common thread in the way academics, clinicians, and the public understand autonomy in place of birth has the potential to bridge this divide.

This concept analysis will not attempt to discover a new general concept of autonomy, but rather examine how the concept and its attributes are presented in the context of place of birth. The aim of the analysis is to explore the use 
of the concept "autonomy in place of birth" in literature and develop a useful definition that draws a sound picture of the complexity of its cultural context, while taking into account the ethical principles of the general concept of autonomy.

\section{Methods}

The background of this article's analysis is the international discussion on childbirth services. Most of the existing theoretical debate has focused on Western civilizations where childbirth services, although generally of high standards, can be structurally different from one region to the next. Hospital-based obstetricians, assisted by nurses, can constitute the most common form of childbirth service in one country, while midwives make up the primary childbirth care in another, regardless of setting (Sandall et al. 2013). Although home birth services are organized very differently worldwide, the health professionals attending the births are usually midwives (Brocklehurst et al. 2011; de Jonge et al. 2013; Grunebaum et al. 2013; Lindgren et al. 2014).

The procedure of the analysis was guided by Walker and Avant's concept analysis model (Walker and Avant 2005). This approach was chosen because it relies not only on literature synthesis but also on modeling and case presentations that describe real life manifestations. The first two steps of the process-selecting a concept and determining the aim of the analysis-have already been taken. The pages following will describe the remaining six steps:

- Identify all uses of the concept that you can discover.

- Determine the defining attributes.

- Identify a model case.

- Identify borderline and contrary cases.

- Identify antecedents and consequences.

- Define empirical referents.

A health literature search was performed in PubMed, Psychinfo, Cochrane, UpToDate, Cinahl, Scopus, and Proquest on keywords such as "birth", "home birth", and "autonomy." Articles that on inspection did not address ethics in childbearing were excluded, along with articles focusing on childbirth autonomy in a specific context other than place of birth. No time limits were applied. The inclusion and exclusion process yielded 26 articles, published from 2001 to 2014, from which seven additional articles, published from 2004 to 2013, were found by a snowball search. All 33 articles (identified in the reference list with an asterisk*) were included in the analysis in addition to general and ethical literature published in books and on websites.

The analyzed material was placed in the context of current evidence on home birth. The end result, a model depicting a woman's autonomy in place of birth (Fig. 1), suggests a common ground for a balanced home birth discussion, in addition to guiding further research on home birth.

\section{Use of the autonomy concept in literature}

The core meaning of autonomy is rooted in the origin of the word itself, which is a combination of the Greek terms "auto", meaning "self", and "nomos", meaning "rule" (Dworkin 1988). Current usage of the word in general language and definitions in dictionaries and thesauruses reveal it to be semantically double-sided. On the one hand, it is synonymous with independence, liberty, and freedom, and is defined as the right to self-government and freedom from the control of others. On the other hand, it is synonymous with self-determination, choice, and will. This latter meaning is not a reference to external rights but to internal qualities - that is, to a person's capacity for exercising self-government (Autonomy [Definition] n.d.; Autonomy [Synonyms] n.d.; Blackburn 1994). These two aspects can be combined by describing autonomy as the capacity of an individual to make an uncoerced decision.

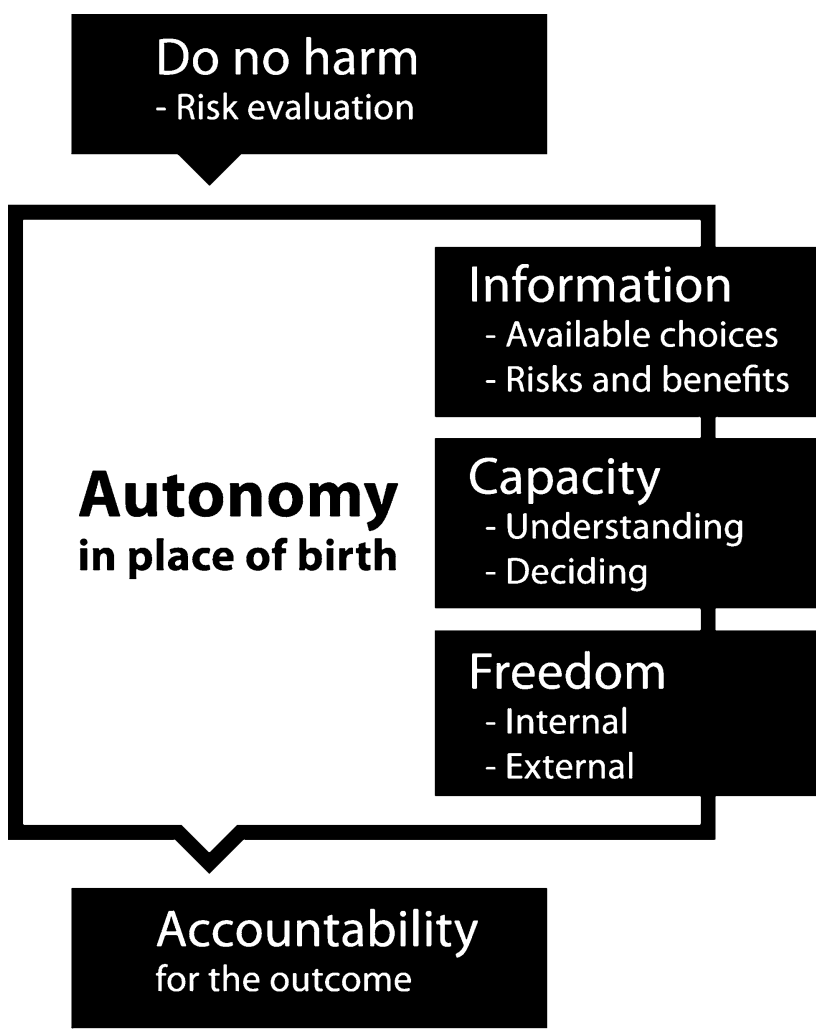

Fig. 1 Defining attributes, antecedents and consequences of autonomy in place of birth 
Autonomy in ethics

The general use of the word "autonomy" reflects the central role it has played in the history of ethics. Immanuel Kant's eighteenth-century deontological ethics advocate a person's right to be free from coercion, stating that an autonomous agent has to be seen as an end and not as means to the ends of others, a stance which equates autonomy with freedom and self-legislation (Beauchamp 2003; Kant 1981). A similar notion is to be found in John Stuart Mill's nineteenth-century utilitarianism, in which the individual is considered the best agent of his or her own well-being. According to Mill, society would be better off letting people live their lives as they themselves see fit, rather than subjecting their will to the demands of others (Mill 1978).

In contemporary philosophy, freedom of choice is considered to be an essential component of autonomy. Real freedom not only includes being free from external coercion from other people, situations, law, or tradition (Árnason 2003; Beauchamp 2003), but also being free from internal coercion, such as the coercive force of addiction (Árnason 2003; Dworkin 1988). Another pillar of autonomy as defined by freedom of choice is the individual's informed understanding of available choices, and the mental capacity for evaluation and decision making (Árnason 2003; Beauchamp 2003; Dworkin 1988).

As a general ethical principle, individual autonomy is not without boundaries; it is limited by the implications of people's choices. It may therefore be ethically justifiable to limit a person's autonomy if his or her actions have the potential to harm another person (Beauchamp 2003). This limitation reflects an opposition to the Kantian theory that autonomy is the ultimate good (Dworkin 1988), acknowledging that sometimes autonomy has to yield to the greater good of another's right to safety. On the other hand, the potential harm to the individual's own interests does not justify limiting the autonomy of an informed, capable individual (Mill 1978).

\section{Autonomy in childbirth health care literature}

The philosophical concept of respect for persons demands that a health professional respect an individual's autonomy while simultaneously caring for his or her well-being-two ethical obligations that can, in practice, contradict one another when the individual's choice is different from what the health professional would consider to be in his or her best interest (Ecker and Minkoff 2011). In childbirth services the health professional has obligations to respect the woman's autonomy while caring for the well-being of both the woman and her unborn baby. The extent of the individual rights of the fetus, and later the unborn baby, has been widely debated and is beyond the scope of this article. In the context of this analysis, it will be assumed that both mother and baby have a set of human rights, although arguably not equal since an unborn baby's capacity for decision making and autonomy is not the same as its mother's (Árnason 2003).

Pregnancy and labor create a unique situation where two individuals are occupying the same body-that of the mother. Their interests are intertwined in a way that makes all ethical discussion challenging at best. Conflicts arise when the autonomy of the woman, her wellbeing and that of her unborn baby cannot be protected all at once. Additional conflicts arise when the woman's perspective on the well-being of the mother-baby dyad are incongruent with the ideas of the health professional (Árnason 2003).

Such conflicts seem to be at the heart of the home birth debate, echoing the previously dominant paternalistic idea of opposed interests of mother and baby inherent in health care services throughout most of the twentieth century. A change in perspectives, exemplified in part by a change in legislation worldwide on patient's rights, is evident in current midwifery models of care in which the woman's choice is deliberately placed in the foreground (Berg et al. 2012; International Confederation of Midwives 2011).

\section{Women's right to information}

An essential part of women's self-determination is to have meaningful access to information on all aspects of the birth services available to them (American College of Obstetricians and Gynecologists [ACOG] 2011; Jouhki 2012; Namey and Lyerly 2010). The pregnant woman needs clinically relevant information regarding her birth, such as the availability of regulated, professional childbirth services in her country, possible effects of various health issues, and transfer time if needed. She should also be informed on available research on likely outcomes and the risk associated with different service options, the reliability of that research, and its applicability to her own situation (ACOG 2011; Chervenak et al. 2011; Symon et al. 2010). Women choosing their place of birth have various sources of information on safety and risk, which play an important role when choosing either home or hospital birth (Murray-Davis et al. 2014). Obtaining, absorbing, and processing this information is an integral part of the process of deciding on home birth (Murray-Davis et al. 2012; Viisainen 2001).

The pregnant woman's right to information must be reflected in the duties of health professionals. It is their ethical obligation to support a woman's autonomy, and thereby her right to choose, by providing the information she needs in an objective manner (Young 2001). When choosing home birth, however, women may encounter obstacles in the form of health professionals who oppose 
home birth, have an uncritical attitude to the hospital norm, and either withhold information or services, or provide outdated information on risk (Association for Improvements in the Maternity Services 2012; Jouhki 2012; Shaw 2007).

\section{Women's intellectual capacities}

Withholding information indicates a certain lack of respect, not only for a woman's autonomy in general (Dworkin 1988), but also for her intellectual capacities in particular. Such views can be related to paternalism and to a health care system in which the main subjects are ill people. Although patients generally retain their capacity for rational thought, their abilities can be affected by certain illnesses. Since intellectual competence is an essential part of autonomy (Symon et al. 2010), its absence can diminish or erase the individual's ability to choose. A midwife or doctor has an ethical obligation to enforce a woman's autonomy by trying to guide her if her choices are based on a serious misunderstanding, on misinformation, or on internal coercion (such as anxiety or addiction), rather than on free and informed rational thought (Symon et al. 2010).

Health professionals must be aware that unlike most other groups of people they attend, pregnant women are generally healthy, not sick. The premise of doubting an individual's decision-making capacities because of illness is not applicable to pregnant women as a group, although pregnant women can also be patients in certain cases. The general assumption should be that pregnant women are in control of their mental capacities and that their autonomy is in no way diminished by the mere fact that they are with child (Harding 2000).

In the United States this assumption has been fought for rather than accepted in the last decades. The public discourse has portrayed mothers challenging the biomedical model as irresponsible (Craven 2005; Ketler 2001). Their mothering practices have been described as pathological and women choosing home birth have been put on a par with drug-addicted mothers (Craven 2005). On the other hand, tidal changes in US court rulings have reflected a shift from the image of the irrational home birth mother to the woman who chooses home birth as an informed consumer, deciding on what she perceives to be the safest choice for herself and her baby (Craven 2005; Ketler 2001). Women's emphasis on safety when choosing home birth has since been established in North American studies (Lothian 2013; Murray-Davis et al. 2014).

Influence and power

Women greatly value their right to self-determination (Hendrix et al. 2009; Lindgren et al. 2010). Autonomy is not only a necessary precondition for informed choice in place of birth; it is also one of the most important benefits that women intend to achieve through the home birth experience, which they associate with autonomy, choice and control (Hadjigeorgiou et al. 2012; Hendrix et al. 2009; Jouhki 2012; Lindgren et al. 2010; Murray-Davis et al. 2012, 2014; van Haaren-Ten Haken et al. 2012; Viisainen 2001). Having the power to shape their birth experience in accordance with their own views and values rather than those of others is the essence of women's self-determination in childbirth (Namey and Lyerly 2010).

The influence of family and friends is an important factor in the decision-making process when a woman chooses home birth, but support from her personal environment is not necessary for her to stick to her choice (Jouhki 2012; Murray-Davis et al. 2012). On the other hand, lack of support or direct opposition from the health care system can be an inhibiting factor (Jouhki 2012; Lindgren et al. 2010). When surrounded by resistance from authoritative figures, a woman's choice is not genuine (Shaw 2007).

Cultural and legal acceptance of home birth, which differs from one Western country to the next, may influence the way women deal with this kind of resistance. Dutch women, who are accustomed to free choice in their place of birth, openly reject external influence (Hendrix et al. 2009). As a small minority, Finnish and British women birthing at home covertly avoid external pressure that stems from biomedical perspectives and find their own way through the system (Shaw 2007; Viisainen 2001). In countries where choice is more oppressed, women have fought in court for their right to autonomy. The European Court of Human Rights ruled in 2010 that the Hungarian government had violated a woman's right to respect for private and family life, by legally prosecuting and convicting health professionals for assisting in home births (Registrar of the European Court of Human Rights 2010). As opposed to this, United States court rulings that have diminished women's rights in order to increase the rights of the unborn baby (Minkoff and Lyerly 2010; Minkoff and Paltrow 2004), have not been overturned.

A woman's freedom of choice depends on the availability of services, as demonstrated by the Hungarian precedent. Unavailability of midwifery services has been found to be a limiting factor in home birth in Sweden, Ireland, and the United States (Craven 2005; Lindgren et al. 2008; Oboyle 2013; Vedam 2012). Given the increasing observational evidence in favor of home birth, and in the absence of sufficient evidence from randomized controlled trials, a recent Cochrane review suggests that health care systems should consider offering home birth care from competent home birth midwives with access to medical collaboration to lowrisk women, who presumably constitute the majority of all pregnancies (Olsen and Clausen 2012). 
Respect for women's autonomy in place of birth should be accompanied by health professionals' respectful participation in regulation and consultation (American Academy of Pediatrics 2013; Minkoff and Ecker 2013; Wendland 2013), and their willingness to refer care to competent home birth professionals if they do not wish to attend home births themselves (Wendland 2013). Midwives and doctors have their own right to be led by their values when deciding whether or not to take part in endeavors that they see as too risky (Beauchamp 2003; Ecker and Minkoff 2011), for example, the home birth of a woman with known risk factors. Nevertheless, ethical decision making based on the principle not to harm might eventually demand that midwives or doctors attend such a birth if the alternative is the woman giving birth at home without assistance, which could carry more risk for mother and baby (Symon et al. 2010).

"First do no harm"

In addition to the restraints of general duties not to harm others, a woman who has decided to carry a child to term voluntarily takes on a set of situation-specific ethical duties towards the unborn baby and its well-being (Árnason 2003; Lupton 2012). Paternalistic societies tend to take those duties a step further, expecting a pregnant woman to behave according to other's ideas on the interests of her unborn baby, and to put the interests of the baby before her own (Lupton 2012); and this is even more so the case in pregnancy, before the woman takes on the role of the mother (Lyerly et al. 2009; Minkoff and Lyerly 2010).

A recent Lancet editorial stated that "women have the right to choose how and where to give birth, but they do not have the right to put their baby at risk" (The Lancet 2010). In theory, such notions are hard to dispute and have led to the perceived duties of health professionals to provide directive counseling, where the professionals possess the knowledge on risk and the woman's choices are not considered ethical if she does not comply with the recommendations she receives (Chervenak et al. 2011). This context of narrow and oppressed choices amounts to a veil of pseudo-autonomy (Shaw 2007).

Restrictions on women's autonomy can be found in recent Icelandic legislation on health professionals' duties to report suspected child endangerment as a result of a pregnant woman's way of life-for example, through substance abuse (Barnaverndarlög 2002). A noncompliant woman's legal autonomy can be temporarily revoked in order to admit her to a suitable health care facility. Such law can in fact enforce a woman's autonomy in the case mentioned in the legislation. The real danger in the legislation lies in the gap left by the "for example." Health professionals are already giving directive advice on various risk-averse behaviors in pregnancy (Lupton 2012). If society is willing to legally state that the best agent of the unborn baby's well-being is someone other than the mother, it is putting itself on a slippery slope towards external control and diminished autonomy for women in childbirth (Minkoff and Paltrow 2004), including choice in place of birth.

Tolerance for uncertainty in health care tends to be low. Rather than accepting that the accuracy of hindsight is a luxury not afforded to those making decisions in health care, health professionals may succumb to a desire for security by presenting an unbalanced risk assessment. One example of such imbalance is emphasizing relative risk while putting aside absolute risk (Ecker and Minkoff 2011). Another example is different approaches to pregnancy versus birth. In pregnancy, the risk of intervention tends to be overrated, while in birth the risk of failing to intervene tends to be overemphasized (Lyerly et al. 2009). A similar duality is evident in the presentation of different places of birth in public media and professional journals, a duality in which the risk of home birth and benefits of hospital birth are highlighted (Armstrong 2010).

The question "when is a risk worth taking" cannot be answered without incorporating the values of those taking part in the calculation (Kukla et al. 2009; Nieuwenhuijze and Low 2013). Childbirth is a profound personal experience, which makes it all the more important that a woman's values be the guiding light in risk assessment in childbirth (Kukla et al. 2009). Women choosing home birth have generally done so after weighing the perceived high risk of loss of control and loss of natural childbirth in hospital against the perceived low risk of serious injury to the baby in home birth (Lindgren et al. 2010; Lothian 2013). Only the woman herself can be the expert on her own interests, which depend on individual values, wishes, and judgment (Árnason 2003). Mutual and equal respect between individuals in both areas of expertise - the professional and the personal-is essential if autonomy is to create a counterbalance to paternalism (Dworkin 1988).

Adherence to external reason is not necessarily an essential part of autonomy. If the conditions for freedom of choice are fulfilled by means of adequate information and decision-making capacities, an individual's choice is considered to be autonomous, even if it is not in accordance with what others would have deemed to be the most sensible option (Árnason 2003; Symon et al. 2010). Autonomy does not demand perfection (Dworkin 1988).

Who will take the blame?

When considering the uncertainty of risk assessment in childbirth, autonomy seems to be a double-edged sword. In 
spite of the Kantian premise of the morality of an action being contingent on intentions rather than outcome (Kant 1981), increased individual agency in decision making can lead to the assignment of blame to the individual when things go awry (Lupton 2012; Namey and Lyerly 2010). What if a woman's choices are followed by severe neonatal morbidity or mortality, despite the very low odds of such an outcome? Who gets to set the bar and decide what odds would count as high or low? When things go wrong, can it ever be stated with certainty that a decision made by an autonomous mother-to-be was in fact the cause of the problem? Or can it ever be stated that it was not?

Parents deciding on home birth are aware that when they go against the norm, they have to know what they are doing and be prepared to take responsibility for their decisions (Viisainen 2001). Swedish and American home birth mothers are generally aware that either they or their baby could be at risk in case of an acute emergency in labor (Lindgren et al. 2010; Lothian 2013). But the Swedish mothers also point out that life is not infallible and neither is hospital care. Babies can die during hospital birth and children can have medical emergencies at any given time in their everyday lives (Lindgren et al. 2010). To what extent do people let their lives be controlled by those uncertainties?

In light of the portrayed risk and uncertainty of birth, it is not surprising that many women choose to surrender their autonomy and hand over their power of choice to a professional in the hope that they will carry the burden of responsibility if things go wrong. The irony of the situation is that when things in fact go wrong, women may choose to sue the midwives or doctors responsible for their care.

Conscientiously and deliberately choosing to hand power of decision over to another person may be seen as an autonomous act (Dworkin 1988). An example of this is a woman that relinquishes control in labor and surrenders her decision-making in the context of a mutually trusting midwife-woman relationship (Parratt and Fahy 2003). But a woman's unwillingness to make decisions is in itself enough to diminish her autonomy, since the will to exercise autonomy by choosing is one of the foundations of autonomy (Beauchamp 2003). Such an impairment of women's autonomy might be remedied by enhancing women's confidence and self-esteem (Kitzinger 2008).

Enhancing women's autonomy in place of birth by enhancing their confidence and will to choose could be achieved through that age-old cornerstone of philosophydialogue. Joint decision-making based on the mutual disclosure of information in a discussion between two equals, the woman and the health professional, might be the key to unraveling the dilemma created by differing views and values (Ecker and Minkoff 2011; Kukla et al. 2009; Nieuwenhuijze and Low 2013).

\section{Results: defining autonomy in place of birth}

When examining the use of the concept of autonomy in the context of choice in place of birth, the defining attributes, antecedents, and consequences of the concept started to emerge (Fig. 1). The original, general idea of autonomy as presented in the literature on ethics was an appropriate starting point for this research, since childbirth health care literature also presents freedom, information, and capacity as key attributes of women's autonomy in their choice of place of birth.

\section{Defining attributes}

Information pertinent to a woman's own situation is the first essential attribute of her autonomy. Reliable information on the available choices in place of birth should be presented in a balanced, respectful manner by the health professionals caring for the woman in pregnancy. Discussion on benefits and risk should be comprehensive and objective, leaving room for the woman's own judgment and values.

The second attribute of a woman's autonomy in place of birth is her own capacity for rational thought. A woman must be willing and able to obtain, understand, and process information, and make decisions that in her opinion suit her situation, even though they might differ from the recommendations of health professionals.

The third attribute of a woman's autonomy is freedom from any coercion that might steer her away from choosing the birthplace that she values most. A woman who is coerced by the internal force of addiction or anxiety might benefit from external efforts to alleviate her ailment, since this internal coercion could also compromise her capacity for decision making. Influence from family and friends seem to strengthen a woman's autonomy and may never be fully separated from her reality. On the other hand, restricted availability or external coercion from the government or its institutions can violate a woman's human rights and should be exercised with extreme caution.

\section{Antecedents and consequences}

Even though the consequences of a pregnant woman's actions can never be known with certainty until they come to pass, genuine intentions not to harm her baby are an antecedent to the autonomous actions of a woman choosing her place of birth. Those intentions are realized in the risk evaluation carried out by the woman with the assistance of her health care providers.

Accountability for the outcome of one's actions can in theory be categorized as the consequence of the autonomy concept. In practice, the difficulty in defining absolute 
causal pathways in health care results in this accountability becoming an abstract notion. Attempts to hold a woman legally responsible for injuries that her baby sustains in labor might therefore be an exercise in futility. But given the inherent duties of the role of the parent, the real life consequences of her choices will always reside with the mother.

\section{Autonomy cases}

To better understand this concept of autonomy in place of birth it is useful to examine a few cases of what constitutes autonomy and what does not (Walker and Avant 2005). What does a model case of autonomy in place of birth look like? Which cases might look autonomous at first glance but do not quite fit the bill? And how would the opposite of autonomy in place of birth present itself?

\section{Model cases}

A healthy, pregnant woman expecting her second child, whose family and society condones various places of birth, is objectively informed on childbirth services and risk by her health professional. She reflects on her choices, incorporating the information with her own values, and chooses a home birth setting because she values intimacy, avoiding intervention, and the beneficial effects on birth hormones and mother-infant attachment that such a setting fosters.

Another model case is a woman expecting her first child in a rural town. She is informed that the secondary hospital birth unit, offering caesareans with spinal anesthesia but no epidural anesthesia, has a high caesarean rate for primiparas compared to the rates of tertiary hospitals and home birth. The woman opts for a hospital birth in the city because she values avoiding a caesarean section and cannot benefit from home birth without elevating her risk in the event of a prolonged and difficult labor.

\section{Borderline cases}

Many choice pathways may seem autonomous at first glance, but are found on closer inspection to have some but not all the necessary elements of autonomy (Walker and Avant 2005). For example, a healthy woman who is objectively informed on childbirth services and risk by her prenatal community midwife is not autonomous if she never sees home birth as a viable option because her riskaverse prenatal hospital midwife strongly disapproves.

Borderline examples could also include women who are misinformed of risks or benefits. A healthy woman deciding on birth in a rural hospital with a midwife-led birth unit is not autonomous if she is only informed on absolute and relative risks associated with transfer but not informed on the benefits of lower intervention rates compared to tertiary hospitals.

\section{Contrary cases}

Further clarification of the autonomy concept can be found in examining cases that are contrary to autonomy in place of birth-that is, cases which reveal none of the concept's defining attributes (Walker and Avant 2005). One such case could be a woman with a history of mild preeclampsia. A difficult induced vaginal delivery at 40 weeks has led to anxiety bordering on posttraumatic stress. In her second pregnancy, the woman reads about the healing power of a natural home birth. The prenatal midwife, who is firmly against home birth, strongly advises against it based on the woman's medical history. The woman chooses hospital birth in spite of a completely healthy pregnancy.

Another contrary case might be a woman who has a previous history of serious alcohol and drug abuse, but is currently "only smoking pot" and does not mention this to her prenatal midwife. They share a passion for natural childbirth, and the midwife strongly advises home birth. Not knowing about the present or previous drug abuse, the midwife omits to inform the woman on the risks associated with home birth under such circumstances. The woman chooses home birth, partly because it is the cheaper option in her country.

\section{Discussion}

This concept analysis is intended to be a starting point for a balanced debate on women's right to choose their place of birth. The authors realize this debate will not subside in the foreseeable future. People will presumably continue to have different opinions on the appropriateness of home birth, since experiences, beliefs, and emotions affect the way people reason and accept the reasoning of others (James 1897).

This subjective tendency has affected the debate on home birth safety and the way information is presented. A recent example of such an effect is a journal article describing the latest meta-analysis on the outcome of home birth, published in 2010. The researchers associated home birth with higher neonatal mortality, using a definition that excluded the largest study comparing home and hospital birth but included several older and smaller studies (Wax et al. 2010). The results have since been widely criticized (Olsen and Clausen 2012).

It may be optimistic to assume that women will receive impartial information and retain their freedom from 
coercion while home birth continues to be a value-laden and emotional subject. Initiatives such as the multidisciplinary Home Birth Consensus Summit in Warrenton, Virginia, in 2011, whose first consensus statement puts the woman's autonomy at the center of her care (Vedam 2012), may lead the way.

It may also be naive to assume that the goal of the majority of modern women is to have a natural birth that is led by their intuitions rather than controlled by external forces. The current trend in Western civilizations favors predictability and welcomes controlled solutions to life's challenges in the form of epidural anesthesia and elective caesarean sections. Should women and health professionals simply accept this trend or should those inclined to a more natural approach have a valid voice and the right to determine their own path?

Parents seem to be acutely aware of their responsibilities when making decisions on behalf of their child, especially when taking the road less traveled (Viisainen 2001). If home birth leads to a harmful outcome for women and babies, the family members themselves will always be the ones most affected. And it follows that they will also be the ones reaping the benefits of a successful birth, which presumably is the goal of every parent choosing their place of birth.

A common understanding of the nature of women's autonomous choice of place of birth enables a discussion of home birth that is inclusive of opposing views. Even though a definition of autonomy in place of birth will not lead to an objective measuring device with defined empirical referents, as suggested by our method of concept analysis, such a definition is applicable to situations in which health professionals or pregnant women are contemplating their autonomy. In today's complex health care systems, embedded in societies with strong prevailing opinions on home birth, tools that encourage reflection on the morality of actions are bound to be beneficial.

\section{Conclusion}

A woman choosing place of birth can be seen as autonomous when she receives all relevant information on the available choices and the risks and benefits involved, is capable of understanding and processing the information and deciding her place of birth in the absence of external or internal coercion, provided she intends no harm to others and is accountable for the outcome. Being autonomous in this sense gives the woman great power in the choices she makes, and equally great responsibilities.

This definition of a woman's autonomy in the context of place of birth can facilitate balanced discussion of opposing views, in addition to being a useful tool in evaluating the moral situation of women and health professionals. The authors hope this tool can and will be used in clinical practice and future debates and studies on home birth.

Acknowledgments This work was supported by grants from the Icelandic Research Fund for Graduate Students and the Memorial Fund of Midwife Bjorg Magnusdottir and Farmer Magnus Jonasson. The article was proofread by Mr. Neal O'Donoghue.

\section{References}

*American Academy of Pediatrics-Committee on Fetus and Newborn. 2013. Policy statement: Planned home birth. Pediatrics 131: 1016. doi:10.1542/peds.2013-0575.

*American College of Obstetricians and Gynecologists - Committee on Obstetric Practice. 2011. Committee opinion no. 476: Planned home birth. Obstetrics and Gynecology 117(2 Pt 1): 425-428. doi:10.1097/AOG.0b013e31820eee20.

*Armstrong, E.M. 2010. Home birth matters-for all women. Journal of Perinatal Education 19: 8-11. doi:10.1624/105812410x482329.

Árnason, V. 2003. Siðfraði lífs og dauða: Erfiðar ákvarðanir $i$ heilbrigðispjónustu [Ethics of life and death: Difficult decisions in health care], 2nd ed. Reykjavík: Háskólaútgáfan.

Association for Improvements in the Maternity Services. 2012. Home birth: Booking a home birth. http://www.aims.org.uk/home birthUpdated.htm\#bookingAHomeBirth. Accessed 5 Sept 2014.

Autonomy [Definition]. n.d. In Merriam-Webster.com. http://www. merriam-webster.com/dictionary/autonomy. Accessed 5 Sept 2014.

Autonomy [Synonyms]. n.d. In Merriam-Webster.com. http://www. merriam-webster.com/thesaurus/autonomy. Accessed 5 Sept 2014.

Barnaverndarlög. 2002. [Child Protection Act] no. 80/2002.

Beauchamp, T.L. 2003. Ethical theory and bioethics. In Contemporary issues in bioethics, 6th ed, ed. T.L. Beauchamp, and L. Walters, 1-37. Belmont: Wadsworth.

Berg, M., O.A. Olafsdottir, and I. Lundgren. 2012. A midwifery model of woman-centred childbirth care-In Swedish and Icelandic settings. Sexual \& Reproductive Healthcare 3: 79-87. doi:10.1016/j.srhc.2012.03.001.

Blackburn, S. 1994. The oxford dictionary of philosophy. Oxford: Oxford University Press.

Brocklehurst, P., P. Hardy, J. Hollowell, L. Linsell, A. Macfarlane, C. McCourt, N. Marlow, A. Miller, M. Newburn, S. Petrou, D. Puddicombe, M. Redshaw, R. Rowe, J. Sandall, L. Silverton, and M. Stewart. 2011. Perinatal and maternal outcomes by planned place of birth for healthy women with low risk pregnancies: The birthplace in England national prospective cohort study. $B M J$ 343: d7400. doi:10.1136/bmj.d7400.

*Chervenak, F.A., L.B. McCullough, and B. Arabin. 2011. Obstetric ethics: An essential dimension of planned home birth. Obstetrics and Gynecology 117: 1183-1187. doi:10.1097/AOG. Ob013e3182172a97.

*Craven, C. 2005. Claiming respectable American motherhood: Homebirth mothers, medical officials, and the state. Medical Anthropology Quarterly 19: 194-215.

de Jonge, A., J.A.J.M. Mesman, J. Manniën, J.J. Zwart, J. van Dillen, and J. van Roosmalen. 2013. Severe adverse maternal outcomes among low risk women with planned home versus hospital births in the Netherlands: Nationwide cohort study. BMJ 346: 1. doi:10.1136/bmj.f3263.

Dworkin, G. 1988. The theory and practice of autonomy. Cambridge: Cambridge University Press.

*Ecker, J., and H. Minkoff. 2011. Home birth: What are physicians' ethical obligations when patient choices may carry increased 
risk? Obstetrics and Gynecology 117: 1179-1182. doi:10.1097/ AOG.0b013e3182167413.

Grunebaum, A., L.B. McCullough, K.J. Sapra, R.L. Brent, M.I. Levene, B. Arabin, and F.A. Chervenak. 2013. Apgar score of 0 at 5 minutes and neonatal seizures or serious neurologic dysfunction in relation to birth setting. American Journal of Obstetrics and Gynecology 209: 323.e1-6. doi:10.1016/j.ajog. 2013.06.025

*Hadjigeorgiou, E., C. Kouta, E. Papastavrou, I. Papadopoulos, and L.B. Martensson. 2012. Women's perceptions of their right to choose the place of childbirth: An integrative review. Midwifery 28: 380-390. doi:10.1016/j.midw.2011.05.006.

Harding, D. 2000. Making choices in childbirth. In The new midwifery: Science and sensitivity in practice, ed. L.A. Page, and P. Percival, 71-85. Edinburgh: Churchill Livingstone.

*Hendrix, M., M. Van Horck, D. Moreta, F. Nieman, M. Nieuwenhuijze, J. Severens, and J. Nijhuis. 2009. Why women do not accept randomisation for place of birth: Feasibility of a RCT in the Netherlands. BJOG: An International Journal of Obstetrics and Gynaecology 116: 537-542. discussion 542-534.

International Confederation of Midwives. 2011. Bill of rights for women and midwives. The Netherlands: International Confederation of Midwives.

James, W. 1897. The will to believe, and other essays in popular philosophy. http://www.gutenberg.org/files/26659/26659-h/26659h.htm. Accessed 5 Sept 2014.

*Jouhki, M.R. 2012. Choosing homebirth-The women's perspective. Women and Birth 25: e56-e61. doi:10.1016/j.wombi.2011.10.002.

Kant, I. 1981. Grounding for the metaphysics of morals. Trans. J.W. Ellington. Cambridge: Hackett. (Original work published 1785).

*Ketler, S.K. 2001. The rebirth of informed consent: A cultural analysis of the informed consent doctrine after Schreiber v. Physicians Insurance Co. of Wisconsin. Northwestern University Law Review 95: 1029-1056.

*Kitzinger, S. 2008. Letter from Europe: Home birth, midwives, and doulas. Birth 35: 250-252. doi:10.1111/j.1523-536X.2008.00249.x.

*Kukla, R., M. Kuppermann, M. Little, A.D. Lyerly, L.M. Mitchell, E.M. Armstrong, and L. Harris. 2009. Finding autonomy in birth. Bioethics 23: 1-8.

Lindgren, H., H. Kjaergaard, O.A. Olafsdottir, and E. Blix. 2014. Praxis and guidelines for planned homebirths in the Nordic countries-An overview. Sexual \& Reproductive Healthcare 5: 3-8. doi:10.1016/j.srhc.2013.12.002.

*Lindgren, H.E., I.M. Hildingsson, K. Christensson, and I.J. Radestad. 2008. Transfers in planned home births related to midwife availability and continuity: A nationwide population-based study. Birth 35: 9-15. doi:10.1111/j.1523-536X.2007.00206.x.

*Lindgren, H.E., I.J. Radestad, K. Christensson, K. Wally-Bystrom, and I.M. Hildingsson. 2010. Perceptions of risk and risk management among 735 women who opted for a home birth. Midwifery 26: 163-172. doi:10.1016/j.midw.2008.04.010.

*Lothian, J.A. 2013. Being safe: Making the decision to have a planned home birth in the United States. Journal of Clinical Ethics 24: 266-275.

*Lupton, D. 2012. 'Precious cargo': Foetal subjects, risk and reproductive citizenship. Critical Public Health 22: 329-340. doi:10.1080/09581596.2012.657612.

*Lyerly, A.D., L.M. Mitchell, E.M. Armstrong, L.H. Harris, R. Kukla, M. Kuppermann, and M.O. Little. 2009. Risk and the pregnant body. Hastings Center Report 39(6): 34-42.

Mill, J.S. 1978. Frelsið [On liberty], 2nd ed, Trans. J.H. Adalsteinsson and Th. Gylfason. Reykjavík: Hið íslenzka bókmenntafélag. (Original work published 1859).

*Minkoff, H., and J. Ecker. 2013. A reconsideration of home birth in the United States. Journal of Clinical Ethics 24: 207-214.
*Minkoff, H., and A.D. Lyerly. 2010. Samantha Burton and the rights of pregnant women twenty years after In re A. C. Hastings Center Report 40(6): 13-15.

*Minkoff, H., and L.M. Paltrow. 2004. Melissa Rowland and the rights of pregnant women. Obstetrics and Gynecology 104: 1234-1236. doi:10.1097/01.aog.0000146289.65429.48.

*Murray-Davis, B., H. McDonald, A. Rietsma, M. Coubrough, and E. Hutton. 2014. Deciding on home or hospital birth: Results of the Ontario choice of birthplace survey. Midwifery 30: 869-876. doi:10.1016/j.midw.2014.01.008.

*Murray-Davis, B., P. McNiven, H. McDonald, A. Malott, L. Elarar, and E. Hutton. 2012. Why home birth? A qualitative study exploring women's decision making about place of birth in two Canadian provinces. Midwifery 28: 576-581. doi:10.1016/j. midw.2012.01.013.

*Namey, E.E., and A.D. Lyerly. 2010. The meaning of "control" for childbearing women in the US. Social Science and Medicine 71(4): 769-776. doi:10.1016/j.socscimed.2010.05.024.

*Nieuwenhuijze, M., and L.K. Low. 2013. Facilitating women's choice in maternity care. Journal of Clinical Ethics 24: 276-282.

*Oboyle, C. 2013. 'Just waiting to be hauled over the coals': Home birth midwifery in Ireland. Midwifery 29: 988-995. doi:10.1016/ j.midw.2012.12.010.

*Olsen, O., and J.A. Clausen. 2012. Planned hospital birth versus planned home birth. Cochrane Database of Systematic Reviews 9: Cd000352. doi:10.1002/14651858.CD000352.pub2.

Parratt, J., and K. Fahy. 2003. Trusting enough to be out of control: a pilot study of women's sense of self during childbirth. Australian Journal of Midwifery 16(1): 15-22.

Registrar of the European Court of Human Rights. 2010. Legal uncertainty prevented mother from giving birth at home [Press release no. 962(3)]. http://hudoc.echr.coe.int/sites/eng-press/ Pages/search.aspx\#\{\%22fulltext\%22:[\%22Ternovszky\%20v.\% 20hungary\%22],\%22sort\%22:[\%22respondent\%20Ascending\%22], \%22prrespondent\%22:[\%22HUN\%22]\}. Accessed 5 Sept 2014.

Sandall, J., H. Soltani, S. Gates, A. Shennan, and D. Devane. 2013. Midwife-led continuity models versus other models of care for childbearing women. Cochrane Database of Systematic Reviews 8: Cd004667. doi:10.1002/14651858.CD004667.pub3.

*Shaw, R. 2007. 'It's your body, your baby, your birth': Planning and achieving home birth. Feminism and Psychology 17: $565-570$.

*Symon, A., C. Winter, P.T. Donnan, and M. Kirkham. 2010. Examining autonomy's boundaries: A follow-up review of perinatal mortality cases in UK independent midwifery. Birth 37: $280-287$.

*The Lancet. 2010. Home birth-Proceed with caution. Lancet 376: 303. doi:10.1016/S0140-6736(10)61165-8.

*van Haaren-Ten Haken, T., M. Hendrix, M. Nieuwenhuijze, L. Budé, R. de Vries, and J. Nijhuis. 2012. Preferred place of birth: Characteristics and motives of low-risk nulliparous women in the Netherlands. Midwifery 28: 609-618. doi:10.1016/j.midw.2012. 07.010.

*Vedam, S. 2012. In search of a common agenda for planned home birth in America. The Journal of Perinatal Education 21: 67-71. doi:10.1891/1058-1243.21.2.67.

*Viisainen, K. 2001. Negotiating control and meaning: Home birth as a self-constructed choice in Finland. Social Science and Medicine 52(7): 1109-1121.

Walker, L.O., and K.C. Avant. 2005. Strategies for theory construction in nursing. Upper Saddle River, NJ: Pearson Prentice Hall.

Wax, J.R., F.L. Lucas, M. Lamont, M.G. Pinette, A. Cartin, and J. Blackstone. 2010. Maternal and newborn outcomes in planned home birth vs planned hospital births: A metaanalysis. American 
Journal of Obstetrics and Gynecology 203: 243.e1-8. doi:10. 1016/j.ajog.2010.05.028.

*Wendland, C.L. 2013. Exceptional deliveries: Home births as ethical anomalies in American obstetrics. Journal of Clinical Ethics 24: 253-265.
Young, R. 2001. Informed consent and patient autonomy. In Companion to bioethics, ed. H. Kuhse, and P. Singer, 441-451. Oxford: Blackwell. 